\title{
Maimónides, pensamiento, influencia y actualidad
}

\author{
Feliciano Delgado
}

El rito de las conmemoraciones centenarias tienen la ventaja de hacer que lo que pertenecía al pozo de la investigación o a los polvorientos rincones de la erudición surja y se manifieste en la claridad de una cultura extensiva. Maimónides era una figura muy presente en el mundo judío, pero era un gran desconocido hasta en su ciudad natal. Este año, el celo infatigable de unos cuantos ha logrado presentar a nivel mundial el 850 aniversario de su nacimiento y ustedes han tenido la atención de invitarme a que yo intente glosar su figura en esta plaza española tan querida.

Toda conmemoración del pasado tiene una peculiar filosofía. No se conmemoran por que sí y siempre algo oculto subyace en esas conmemoraciones $\mathrm{y}$ ciertas finalidades se pretenden. Algunos han pensado que hemos potenciado esta conmemoración del 850 centenario como una forma de preparar políticamente el reconocimiento del Estado de Israel. Puedo asegurar que no estaba ésto presente en el ánimo de los organizadores. Sin manifestarlo abiertamente, si teníamos en el fondo una idea surgida de una preocupación histórica. En los últimos años en Andalucía, por parte de algunas fuerzas políticas, de cuya fuerza nunca se está seguro, ha habido una potenciación del sustrato arábico de nuestra región. Se ha potenciado tremendamente lo islámico. No es un secreto decir que Libia ha intentado y está intentando potenciar su presencia cultural al lado de su evidente presencia en la economfa. A su lado la cultura judía ha estado siempre presente en Andalucía, pero se ha puesto poco de manifiesto. Al lado de nuestro pasado romano evidente, de nuestra tremenda cultura visigótica y de una cultura árabe, existió una enorme cultura judía que ha influído mucho en la configuración del ser de Andalucía y de España. No es tan fácil de captar porque muchos de sus elementos se diluyen en el cristianismo, porque no en valde el cristianismo incluye much ísimo de la tradición judía en su doctrina. También nos damos cuenta de que los judíos españoles, hoy a través de muchas dificultades, siguen existiendo y manteniendo unas tradiciones que son judías, pero son judías españolas. Me refiero a todo el mundo del sefardismo. Por todo esto es importante recordar a un viejo maestro y que su figura nos ayude a esclarecer una parte importante de nuestro pasado. Que los neo-muladíes se den 
cuenta de que junto a los islámicos, árabes o moros, existieron unos españoles de religión judía, que vinieron en tiempo romanos, que se asentaron en esa atormentada piel de toro de la península, que desarrollaron una Edad de Oro de la literatura judia, que fueron expulsados de España y que son los últimos de los exiliados que todavía no han vuelto.

Maimónides es el filósofo judío más grande de ese pueblo. Pero cuando se dice filósofo judío la expresión puede quedar ambigua. Hay filósofos judíos como Espinoza, Marx o Freud, cuyo pensamiento se explica en parte por su condición judía. Son judios y su pensamiento viene parcialmente determinado por su creencia y formación, pero en cuanto a la totalidad de su contenido, su pensamiento sobrepasa el esquema del juda ísmo. Maimónides es filósofo judío en el sentido absoluto del término. Se trata de un filósofo en el que el punto de partida de su filosofía parte del judaísmo, se nutre en el judaísmo y revierte a la comunidad judía principalmente. Maimónides crea un pensamiento en el que el judaísmo da sentido a la línea de su investigación, que produce cierta teología judía y que desde entonces se le considera en casi todos los ambientes judíos como el representante más autorizado del pensamiento y de la tradición del judaísmo. Se puede decir que el judaísmo, hasta el siglo XVIII, son tres cosas: La Tohra, o Pentateuco, que es la ley, pero en su sentido específico, como veremos, El Talmud, que es la enseñanza escrita y el comentario y Maimónides, que es la última codificación sintética del judaísmo ortodoxo.

Quisiéremos poner de manifiesto qué lugar ocupa en la historia del pensamiento y por eso vamos a enunciar brevemente su biografía y vamos a insistir más en el sentido total de su obra.

Nace en Córdoba en 1135, es decir, en pleno esplendor del Califato. Antes de la conquista de Andalucía por el Islam existía un fuerte comunidad judía en Córdoba y su provincia. La situación de libertad que mantenían en el Imperio Romano varió profundamente con la conquista visigótica. Sisebuto, en el 612 comienza la era de persecuciones y obligación de elegir entre la conversión o el exilio. Estas disposiciones culminan en el Concilio de Toledo de 694 donde se acusa a los judios de subversión política y de intentar una alianza con los judíos del otro lado del estrecho. Esto explica que con la conquista árabe la comunidad judía de Al-Andalus encontraran en los árabes una liberación. En Córdoba se extiende la comunidad judía y en un responsum de Natronay, gaón de Sura se dice de Lucena que era una ciudad judía sin un solo gentil. La comunidad judía de Córdoba vivía en un barrio muy cerca de la Mezquita, aunque es posible que allí sólo viviera el núcleo intelectual e influyente porque debía de haber otro asentamiento en las afueras, con su puerta especial en la muralla, la Bab al-Yahub, puerta de los judíos (L. Torres Balbás, "Mozarabías y juderías de las ciudades hispano-musulmanas", Al-Andalus, 19 (1954) 174-197. Lévy Provenzal, Institutiones, pág. 127).

Para dar idea de como era su vida en ese instante nos bastará ver en un 
texto cómo veían ellos a Córdoba. Hay una carta del célebre médico Hasday ibn Saprut contemporáneo y cortesano de Abdel-Rahman III y Al-Hakan II al rey de los Jazares. Dice allí: Es una tierra -al-Andalus- fértil, llena de ríos, fuentes y pozos horadados, tierra de trigo, vino, aceite, múltiples y deliciosos frutos y de todo género de cosas preciosas. Tiene jardines y huertos donde crece todo tipo de árboles frutales y donde florecen árboles cuyas hojas comen los gusanos de seda. La seda, precisamente, la tenemos nosotros en gran abundancia. Tenemos asimismo montes con azafrán de muchas especies. Tenemos en nuestro país minas de plata y de oro, montes de los que se extrae el cobre y se saca el hierro, el estaño, el plomo y el zinc, el azufre, el mármol, el cristal, minas de los que en lengua árabe se llama ll'wn'. Y decía al comienzo de la carta. "El nombre de nuestro país, en cuyo medio habitamos es Sefarad en la lengua santa, mientras que en la lengua de los árabes que residen en el país es Al-Alandalus. El nombre de la capital del reino es Córdoba. Su longitud es de 25.000 codos (codo, $52 \mathrm{~cm}$.), y su anchura diez mil".

En esa Córdoba, nace dentro de una familia distinguida. En un ambiente de cultura judía que había y estaba desarrollando una escuela talmúdica y una escuela filológica. En esta época (I. Abraham, Jewish Life in the Middle Ages. New York, 1958, pág. 348), el niño judío comenzaba sus estudios a los cinco años. Los estudios primarios eran sostenidos por la comunidad o por personas privadas. Los secundarios por la comunidad. La enseñanza superior se impartía en la sinagoga. En España había una escuela en Córdoba ya en el siglo X, como sabemos por el testimonio de Ibn Daud en su Sefer ha-Qabbala. La enseñanza islámica se impartía en la mezquita. Los jóvenes judíos recibirían esas enseñanzas por el conocimiento y uso que hace la comunidad de al-Andalus del árabe y por su interés por otras materias profanas, como geografía, matemáticas y medicina. Al alcanzar el rasgo de mito, la vida real de Maimónides se ha mezclado con la leyenda. Pero dentro de esas leyendas puede ser real el que su padre lo llevara a Lucena para que lo bendijera el rabino Jain Joseph Ibn-Minguez "el rabino lo bendijo antes de exaltar el último suspiro". Nos lo cuenta Jaim Joseph Ibn Azulay en su Léxico.

A los trece años comienza a recibir el tremendo desastre de la guerra. La tranquilidad de los omeyas se ve destrozada por una secta revolucionaria y fanática. Los Almohades (al-Muwahhidum, "los unitarios") que conquistan Córdoba en 1148. Aplican la ley extrictamente y los judios o tienen que convertirse o marcharse. Los Maimónides practican su fe ocultamente durante 11 años y cuando esa doble vida se hace imposible emigran a Fez. Allí Maimónides continúa su educación en los estudios judaico, en la filosofía griega y sobre todo en la medicina. Allí se mantenía la misma disciplina almohade, pero es posible que pudieran pasar más desapercibidos. En 1165, el maestro de Maimónides, el rabino Judah Ibn Shosham es acusado de practicar su fe y es ejecutado. La familia huye a Palestina. Pero allí los medios de vida no eran demasiado buenos. Después de unos meses se mudan a Egipto 
y se asientan en Fostat, cerca del Cairo. Al poco tiempo de llegar allí muere su padre y su hermano, un mercader de piedras, en un naufragio y con él se pierde el dinero de la familia, del que dependía Maimónides. No puede volver al rabinato porque era considerado como un servicio público y no recibía remuneración. Maimónides se aprovecha de sus estudios médicos y comienza a practicar la medicina. Su fama se estiende y se convierte en médico del sultán Saladino y de su hijo al-Afdal. Al mismo tiempo se constituye en lider de la comunidad judia hasta el momento de su muerte. En esas circunstancias de trabajo y tensión realiza su obra, que es lo que le hace y constituye en valor permanente.

Nosotros quisiéramos, más que hablar de su obra, comprender cómo se produce dentro del pensamiento judio, por ser este punto desgraciadamente poco conocido.

A Maimónides hay que colocarlo como un último exponente del movimiento rabínico. Si no se hace así es posible que no podamos entender su figura.

El movimiento rabínico surge cuando los romanos acaban con la rebelión de Bar Kokba en Palestina y termina la resistencia (135-136). Los romanos comprenden que ya no existe posibilidad de resistencia por parte de los judíos y no aplican las leyes de Hadriano de prohibir las asambleas públicas y permiten la creación de centros de estudio como la academia de Usha en Galilea.

En ese momento aparecen los rabinos judíos como una fuerza social. La fuerza de los rabinos reside en la habilidad de representar simultáneamente el interés de judíos y romanos, cuyas necesidades religiosas y políticas, por suerte, coinciden en este momento. Los rabinos son mirados por los romanos favorablemente por ser una clase políticamente sumida, que por su gran influencia sobre las masas judias pueden traducir la Pax Romana en preceptos religiosos judíos. Para los judíos, por otra parte, la ideología rabínica da una continuidad a su independencia de gobierno interno. El programa rabínico, que presenta y extiende Johanan ben Zakkai, reemplaza el sacrificio y la peregrinación al templo de Jerusalem por el estudio de la escritura y como premio a esa acción la consecución de la restauración del reino de David y personalmente la seguridad en una resurrección y la participación mistica en un renacimiento universal.

En este ambiente, el príncipe Judah (175-220) en la llamada edad de los tannaim (maestros), poseyendo poder económico, respaldo romano y legimidez dinástica, puesto que descendía de David, sońó con regularizar la práctica de la comunidad judía a través de la creación de un corpus legal que recogiera los puntos de vista del rabinato sobre cada aspecto de la vida cotidiana. Así nace la mishna (colección de leyes rabínicas) y esa compilación se constituye en el punto central y materia de estudio de las escuelas. El conjunto de esos estudios o su prolongaciones el Talmud (enseñanza) comentario a la mishna. 
Anteriormente a la obra legisladora de Judah existían colecciones formadas en el siglo I y II, sobre comentarios a la Escritura y aplicaciones a las situaciones difíciles. Así surgen los midrashim, plural de midrash, "investigación", "in terpretación", recogidos en tersa prosa legal.

Judah, aunque acepta las formas anteriores compila una nueva colección en la que recoge puntos de vista universalmente aceptados y otros todavía en disputa y así reduce las posiblidades de divergencia en la interpretación de la ley y crea un principio de unidad. A pesar de la oposición de algunos rabinos crea una colección jurídica con una autoridad casi canónica que será la mishna o nuestra mishna, por excelencia.

Como la expresión era a veces obscura o demasiado densa, pronto se le añaden los Adiciones o Tosefta. En los siglos III y IV se le aumentan discusiones de cómo se han llegado a formular los preceptos.

La promulgación de la mishnā inició el período de la historia del pensamiento judío de los amoraim (intérpretes) que hicieron de la mishnā la base de su interpretación. El conjunto de esas interpretaciones se recoge en forma de comentarios a la mishnā que es el Talmund, "enseñanza", con dos colecciones fundamentales, el Talmud palestiniano o de Jerusalem y el Talmud pérsico y de Babilonia, según las dos comunidades judías donde se produce. A veces la palabra Talmud, designa conjuntamente las dos colecciones conjuntas.

Como base fundamental y fundamento de la mishna y del Talmud está la Escritura. La Escritura tiene tres partes fundamentales: el Pentateuco, los cinco libros de Moisés (Génesis, Exodo, Levitico, Números y Deuteronomio), es decir, la Torāh, los Nevi'im, los Profetas y Ketubim, los escritos. Lo fundamental es la Toräh. La palabra viene de una raíz que significa enseñanza, camino, dar la dirección. Es algo más que una guía. Es el camino que da Dios para aprender a vivir. Es una norma entregada de lo alto y por eso da una seguridad el poder caminar por ella, porque es un camino entregado por el pacto que Dios hace con su pueblo. Es la "Torāh min ha-shamayim", la Toräh de los cielos. La palabra ley falsifica el sentido de la Torāh. Desde una amplia perspectiva, la Torāh es el contenido total del judaísmo. La Torāh son sus escrituras sagradas, sus tradiciones orales, sus formulaciones teológicas, sus recuerdos históricos, sus obligaciones éticas, sus rituales, sus observaciones ceremoniales y la misma interpretación autoritativa de los textos.

Con este ambiente o fundamento religioso hay que comprender LA OBRA DE Maimónides. Si se separa de éste y se quiere simplemente relacionarlo con la filosofía griega se pierde el sentido de su figura.

Los escritos de Maimónides son variados y diversos.

A los 16 años escribió el Milot ha-Higgayon (Tratado de terminología lógica) estudio de términos empleados en lógica y en metafísica. Lo escribió en árabe igual que su siguiente libro, que sólo se nos conserva en una traducción hebrea, el Ma'amar ha 'ibur o Ensay o sobre el calendario.

La primera de las obras mayores de M. la comenzó a los 23 años y la 
terminó a los 33. Se trata de Kitab al Siraj. Es un comentario a la Mishnā escrito en árabe, donde va esclareciendo palabras y frases, recurriendo a la arqueología, teología, ciencia. Lo más importante son las introducciones donde expresa la filosofía que dirige la Mishnā. Ahí se encuentran los trece artículos de la fe judía que han pasado a todos los libros de oraciones judaicas. Este credo dice así:

Creo absolutamente que Dios no tiene cuerpo ni se le puede atribuir ninguna creaturas existentes, y sólo él cré, crea y creará todas las cosas.

Creo absolutamente que Dios es uno y que siempre lo fue lo es y lo será y que no existe unicidad como la suya

Creo absolutamente que Dios no tiene cuerpo ni se le puede abribuir ninguna forma ni imagen corporal.

Creo absolutamente que Dios existía antes que nada existiese y que existirá cuando todo haya desaparecido.

Creo absolutamente que sólo a Dios debemos dirigir nuestras plegarias y a nadie más debemos orar.

Creo absolutamente que los profetas han sido inspirados por Dios y sus palabras son verdad.

Creo absolutamente que Moisés fue el mayor de los profetas y que su profecía fue verdadera.

Creo absolutamente que la ley que actualmente conocemos es la misma que fue dada a Moisés en el Sinaí.

Creo absolutamente que la ley nunca cambió ni cambiará

Creo absolutamente que Dios conoce todos los actos y pensamientos humanos por más recónditos que sean.

Creo absolutamente que Dios recompensa las buenas acciones e inflige castigo por las malas.

Creo absolutamente en la llegada del Mesías y aunque tardare, a pesar de todo, lo esperaré cualquier día.

Creo absolutamente que Dios resucitará a los muertos, cuando esa sea su voluntad y se perpetuará su memoria por siempre jamás hasta la consumación de los siglos.

Al terminar su comentario comenzó su magna obra en la que trabajó durante diez anos, la Mishne Torah o ley revisada o segunda ley. Revisión de la ley. Quiso hacer un libro claro y preciso donde se unificaran todas las largas 
discusiones talmúdicas. Lo fue escribiendo poco a poco y al final resultaron 14 libros. Lo importante del libro es que M., parte de un dato absoluto: "La base de las bases y el fundamento de la sabiduría es conocer la existencia del ser supremo". Partiendo de esa base unifica todos los saberes. Se juntan -frente a los cariítas-tradición y autoridad, por eso no cita nombres de maestros, el pasado de Israel y su presente, el alma y el cuerpo, lo actual y la esperanza mesiánica. Este libro estaba escrito para el pueblo. A continuación tenía que escribir su libro para los intelectuales. Ese libro es, escrito en árabe con el título de Dalat al-ha'irin, traducido al hebreo casi a la muerte de Maimónides, con el título de Moreh nebukim, que corresponde al español, Guía de Perplejos. Se trata de la unión más exacta entre ciencia, filosofía y religión. La obra la comenzó en 1176 y trabajó quince años en ella.

No podemos hablar de sus obras menores, ni de su obra médica por incapacidad de conocimientos en esta materia y falta de tiempo, pero bueno es recordar la oración que hacía cada mañana antes de comenzar su tarea médica.

Y su plegaria era así:

"Me estoy preparando para ejercer mi profesión; ayúdame, joh Dios!, en mi trabajo para que tenga éxito.

" iPon en mi corazón el amor a la sabiduría y el amor a tus criaturas!

" ¡Aparta de mí la codicia por los bienes materiales y los honores, pues estas cualidades se oponen a la verdad y al amor al prójimo!

"Fortalece mi cuerpo y mi alma para poder siempre ayudar al pobre y al rico, al bueno y al malo, al amigo y al enemigo; para que vea en el enfermo 'sólo al Hombre'.

'Da a mis enfermos el sentimiento de confianza en mí y en mi ciencia; que presten atención a mis consejos y cumplan mis órdenes.

"Aleja del lecho de los que sufren a todo mediacastro, manosanta y curandero, $y$ a los que creen en ellos.

"Hazme fiel ejecutor de las indicaciones de sabios médicos, hombres de ciencia auténticos, pues el campo de la sabiduría es grande y amplio.

'Dadme el coraje y la fortaleza del espiritu necesarios para combatir a los necios embaucadores que pretenden engañarme, para que no me aparte del camino de la verdad".

Murió a los sesenta y nueve años. En la madrugada de un lunes, el 20 de Tévet de 4965,1204 . Antes de morir había redactado un precioso testamento.

"Oídme, hijos, que habéis sido bendecidos por Dios, Creador del cielo y la tierra..., sed fuertes y haceos hombres; temed al Dios de vuestro padre, de Abra- 
ham, Isaac y Jacob. Servidlo con fe y con amor, pues el temor hace cuidarse del pecado, mientras que el amor impulsa a cumplir los mandamientos divinos."

Y continúa especificando cada uno de los puntos:

- Distinguid bien la aluz de la oscuridad, y apartaos de la muerte y del mal, elegid siempre la vida y el bien, pues la elección está en vuestras manos.

- Observad siempre buenas costumbres, pues la naturaleza del hombre depende de las costumbres y viceversa.

- Absteneos de participar en reuniones fútiles, de la vagancia y del ocio, pues de all provienen los frutos del mal.

- Frecuentad en lo posible las reuniones de los sabios, mas con modestia y sumisión y ocupando los lugares menos destacados...

- Prestad atención y aguzad el oído para saber qué es lo que ellos elogian y qué es lo que desechan.

- No os ufanéis en su presencia y no temáis preguntar lo que no os resulta claro. Sólo cuidad de hacerlo en el momento preciso y con las palabras adecuadas.

- Rondad las casas de los sabios y estudiosos; por alli debéis pasearos...

- Hablad con vuestras mejores palabras, en un estilo refinado y culto, con voz agradable y siempre con respecto al tema que se está tratando, dando la impresión que buscáis realmente la verdad y no que estáis armando camorra.

- Emulad a los eruditos, y despreciad en vuestro interior a los necios.

- Estudiad mientras sois jóvenes y vuestro corazón está libre, y no esperéis a que la mente se llene de pensamiento y se debilite la memoria, pues vendrá entonces un momento en que querréis y no podréis.

- Cuando encontréis un escrito difícil e intrincado, y una cita un tanto rara en la Tora, los libros de los profetas o los hagiógrafos, que os resulte indescifrable y que contradiga los principios de la Torá, no os alarméis y no dejéis paso a la perplejidad. Haced caso omiso del intelecto y no os apartéis de vuestra fe por causa de ese detalle.

- Preferid siempre la verdad y la justicia, por más, que os parezca que resultaréis perjudiciales defendiéndolas, y que por la vía de la impiedad y la mentira os beneficiaréis. Sabed que la verdad y la justicia son joyas del alma y dan fuerza y seguridad de uno mismo.

- Vivid con dignidad, pureza de espíritu y honradez, y no os acerquéis a lo que no os pertenece, ni os guieis por principios que no os resulten absolutamente claros. 
- Acercad a los apartados, enseñad a los incultos y proteged a los desamparados, cuidando de no humillarlos con vuesto óbolo.

- No sacrifiquéis vuestras almas ni vuestros pensamientos al cuerpo ni al dinero, pues de ser así, ¿qué os queda ya?

- Yo he visto que por culpa de las riñas y peleas se han enturbiado los puros, han disminuido los numerosos, familias han sido deshechas, ministros han sido relevados, grandes ciudades han decaido, comunidades se han dividido y los adeptos se desmembraron; los creyentes se transformaron en herejes y los encumbrados perdieron sus honores por causa de las vanas discusiones.

- Conducíos con modestia, pues ella os permitirá escalar elevadas posiciones.

- Someted la materia al intelecto, es decir, el cuerpo al alma, pues de su esclavitud depende vuestra libertad.

- Comed sólo lo suficiente para vivir, y absteneos de lo superfluo.

- En las comidas de camaradería se advierte si una personas es o no culta (es decir, en los ágapes colectivos es posible conocer a las personas por sus maneras).

- Sed caritativos al máximo.

- Honrad a vuestras esposas, pues ellas son vuestra honra.

$\mathrm{Su}$ cuerpo fue trasladado a Israel y lo enterraron, a esperar la resurrección mesiánica en Tiberiades. Un anónimo escribió en su tumba:

Aquí yace un hombre y sin embargo no era un hombres.

Si tú fuiste un hombre, entonces te engendraron criaturas celestes.

Como a su muerte surgió la polémica y la envidia, otra mano anónima borró el epitafio anterior y escribió:

Aquí yaces Moisés Maimuni, el hereje desterrado.

Pero en su monumento se escribió:

No hubo nadie de Moiśes a Moisés comparable a Moisés. Samuel Hanagid (993-1056).

\section{Cantos y proberbios}

\section{Guerra}

La guerra es en su comienzo como una hermosa muchacha, con la que todos los hombres sueñan con jugar.

Pero al final es como mujerzuela repulsiva, cuyos seguidores sólo se duelen de ella y lloran. 


\title{
El "Medio" y su importancia en la E.G.B.
}

\author{
Adoración Perpen Rueda
}

La imperiosa necesidad de acometer un estudio del medio en la E. G. B., viene determinada por el hecho de que en la realidad social y escolar nos encontramos que, en la actualidad, la información que al niño llega de fuera supera la cantidad de información comunicada por la instrucción y los textos en la escuela (1).

Este hecho, hace que el libro de texto no sea ya el único soporte de la enseñanza, y que ésta plantee salir en busca de la información al exterior por métodos activos, como complemento de la enseñanza escolar.

Así pues, el estudio del medio, su inclusión en los programas, es el más feroz ataque que podemos hacer a la didáctica tradicional que aún hoy perdura (2).

Pese a lo que podamos pensar, este acercamiento de la E. G. B., al medio no es algo novedoso que hay surgido en fechas recientes. Por el contrario, ya Comenio, exigía que la educación de los niños partiera de su entorno, y, en el siglo XVI, Rollin, se refería a la instrucción de los niños a través de las obras maravillosas de la naturaleza y del arte. Pero, sin duda, el precursor de esta idea fue, Rousseau, quien nos dice que "la educación nos viene de la naturaleza, o de los hombres o de las cosas..."

\section{DEFINICION DE “MEDIO”}

Es evidente que por "medio" no entendemos sólo el medio físico, el sensorial e inmediatamente perceptible o el presente, sino todo el complejo de elementos y relaciones en los que el individuo se encuentra inmerso directa o indirectamente. En el caso del adolescente, el "medio" no es sólo padremadre-casa-amigos, sino también sus ídolos preferidos y cualquier cosa que vea en la televisión; para el adulto, el ámbito crece: familia-trabajo-barrio, y

(1) OLIVAN VILLACAMPA, Carlos: Conocimiento del entorno. Apuntes de Educación núm. 16. Madrid, enero-marzo, 1985 , pág. 8.

(2) GONZALEZ HERNANDEZ, Angel: Didáctica de las Ciencias Sociales. Barcelona, Ceac, 1980, pág. 59. 
estructuras más amplias de costumbres, mentalidades, organización social y política, marco geográfico y evolución histórica.

Todo lo que actúa sobre nosotros, nos mueve y nos orienta, nos hace madurar o progresar, nos plantea problemas o nos impone elecciones, constituye nuestro "medio".

Desde un punto de vista psicológico, el concepto de "medios" es fundamental. La investigación psicológica sobre la evolución del niño sólo es concebible en términos de "relación de interacción" constante entre éste y su ambiente. Esta relación es, al mismo tiempo, un proceso de progresiva diferenciación entre los dos términos (3). Se ha llegado a decir que esta relación es tan estrecha, que lo que nosotros conocemos del niño no son más que las modificaciones que el ambiente provoca en él.

La vida del adulto quedará marcada. Su capacidad de ser consciente de su propia posición en un marco familiar, social, de sus propias posibilidades de elección, dependerán ampliamente de la historia de su relación con la realidad que le envolvió en su infancia y adolescencia.

Una apreciación que habría que hacer en torno a la definición de "medio", es que, aunque en la vida cotidiana utilizamos los términos "medio"y "entorno" indistintamente, no siempre ocurre así. Es el caso, por ejemplo, del Departamento de Pedagogia de la Facultad de Filosofía y Letras de Palma de Mallorca, quien distingue entre estos dos términos: "no nos parece tan adecuada o correcta la denominación de 'entorno', porque supone un término que quizá no acepte tantas matizaciones y significados como el de "medio", pues éste, además de referirse al mundo de lo orgánico, integra también los aspectos supraorgánicos, tanto a nivel sincrónico como diacrónico (4).

Modestamente opinamos, que la práctica educativa no debe perderse en juicios semánticos tan minuciosos y debe atender a estar informada en una triple dimensión:

1) El conocimiento del "medio".

Supone una recogida personal de toda aquella información necesaria para entender la realidad próxima.

2) La expresión del "medio".

La comunicación de la realidad implica el conocimiento de una serie de lenguajes que permiten codificar nuestra experiencia activa sobre el "medio".

3) La transformación del "medio".

Entendida como una actividad física y mental sobre la realidad, que im-

(3) CHIESA, Benvenuto: Razones pedagógicas de la investigación del medio. Cuadernos de Pedagogía, núm. 10, octubre 1975.

(4) Departamento de Pedagogía de la Fac., de Filosofía y Letras de Palma de Mallorca: El medio como experiencia educativa. Cuadernos de Pedagogía, núm. 41, mayo 1978. 
plica la formación de unos esquemas críticos posibilitadores de un replanteamiento constante de las situaciones y hechos de la vida social.

Hay que señalar que los tres puntos anteriormente expuestos suponen una mera formulación didáctica, puesto que no existe una aplicación cronológica de estas tres fases.

\section{EL MEDIO LOCAL Y SU RELEVANCIA}

El medio local constituirá siempre para el maestro y sus alumnos una fuente inagotable de informaciones y enseñanzas que significarán una poderosa ayuda en la enseñanza diaria, como apoyo de los textos.

La escuela no puede ignorar esto, porque forma parte del medio local, y no puede encerrarse en sí misma como los muros hostiles de una cárcel (5).

El "medio" que rodea a la escuela es una fuente privilegiada de recursos materiales y también de personas de la comunidad que pueden informar directamente sobre muchos aspectos del entorno. El extraer del propio "medio" recursos para el aprendizaje conecta al niño con los temas y objetos cotidianos, participando activamente en su recogida, confección y mantenimiento. La realidad circundante es una fuente inagotabble de recursos. Es necesario, pues, construir inventarios de "medios", no sólo de aquellos que pueden llevarse del ambiente a la escuela, sino de los que el entorno ofrece para utilizar en su propio lugar: museos, fábricas, y la propia naturaleza.

El profesor debe planear actividades diversas para realizar en distintos lugares y complementar en el aula y otros espacios culturales lo que el "medio" concreto -urbano, rural, agrícola, minero, industrial-, no subraye directamente.

Muchos de los objetos y materiales de la vida diaria pueden ser en la escuela recursos muy prácticos. También el propio edificio de la escuela y las zonas contiguas al mismo.

Así pues, en cualquier curriculum son necesarios actividades fuera del aula para observar directamente aquellas situaciones de la realidad no trasladable al aula.

\section{EL MEDIO EN LAS CIENCIAS SOCIALES}

No hay medios distintos: histórico, geográfico y biológico, sino un entorno único, determinante de modos de investigación diversa. Su aprovecha-

(5) FAURE, Raul: Medio local y geografia viva. Barcelona, Laia, 1977, pag. 15. 
miento favorece una mutua penetración de disciplinas, hasta ahora compartimentadas. Ahora bien, como nuestro campo de acción es el ámbito de las Ciencias Sociales en la Escuela de Magisterio, lógicamente incidiremos en la ayuda que el "medio" nos proporciona para conocer las realidades geográficas e históricas, $y$, sobre todo, las realidades geográficas e históricas de la localidad.

Todo "medio" se define por un marco espacial y por una dimensión temporal. En consecuencia, hay que utilizar las posiblidades históricas del entorno, así como otros documentos y referencias propuestas a la reflexión del niño, para ayudarle a pasar, en Historia, del nivel de lo vivido al de lo ideado, de la observación a la explicación (6).

El conocimiento de la Historia local constituye un elementos de primer orden para conseguir que el niño empiece a desarrollar la curiosidad, su actitud de búsqueda y de investigación, su ansia de explicaciones satisfactorias. $\mathrm{Si}$ el nino no conoce la historia de su localidad ¿Cómo va a motivarse para comprende realidades históricas más alejadas en el tiempo o en el espacio? Hay que ir, en definitiva, de lo particular a lo general.

La forma de conseguir ese acercamiento a la "investigación" histórica de la localidad, para los niveles de la E. G. B., es mediante la visita e inspección de los Archivos locales o las Bibliotecas, testigos mudos del pasado, no olvidando las limitaciones, a este respecto, que impone la edad escolar.

Así, el documento, junto con la ilustración del maestro, constituye el punto de partida para comenzar a estudiar la historia del "medio" en el que el niño se desenvuelve. Más, siempre que sea posible, no debemos limitarnos a la sola documentación. Hay que aprovechar todas las posibilidades del "medio" para enfrentar al niño con los vestigios del pasado.

En el caso de la Geografía, las posibilidades siguen siendo múltiples. Aquí, los archivos y bibliotecas dejan paso a la observación directa de la realidad: accidentes geográficos de la localidad, modificaciones en el paisaje, distribución de la población, estudio y observación del clima local, etc.

Pero el medio es algo mucho más amplio, que hace conectar distintas disciplinas cuando acometemos su estudio. Disciplinas que, tradicionalmente, tenían vida propia y separada, como compartimentos estancos. He aquí el gran valor del medio: su carácter globalizador, de máxima importancia en los ciclos Inicial y Medio de la E. G. B.

Veamos, en el siguiente cuadro, como confluyen las distintas disciplinas a la hora de estudiar la "Comunidad", una unidad temática de 5.0 de E. G. B. (7).

(6) LUC, Jean-Noel: La enseñanza de la historia a través del medio. Madrid, Gncel-Kapelusz, 1982, pág. 36.

(7) I. E. P. S. Historia en el aula. Madrid, Narcea, 1982, pág. 41. 
Geografía y C. Naturales.

El paisaje de mi comu-

nidad.

Iniciación al relieve,

hidrografía y clima.

Fauna y vege tación.

\section{Antropología}

Peculiaridades

culturales.

Costumbres y fiestas.

Folklore, música y gas-

tronomía.

Monografías

El comercio.

Vías de comunicación:

carreteras, ferrocarriles

y puertos.

Comercio interior $y$ exterior.

Economía

De qué vive $\mathrm{mi}$

comunidad.

Agricultura, ga-

nadaría e industria.
Fistoria

¿Quiénes habitan mi

comunidad?

Monumentos.

Personajes ilustres.

\section{Demografía}

Población y pirámide de

edad.

Zonas más pobladas, pueblos y ciudades.

Sector de actividad.

Política y Administración.

Organización municipal.

Administración de justicia.

Organización militar.

\section{COMUNIDAD}

Como podemos observar, la interacción entre los aspectos naturales y sociales del entorno es enorme. Esto es asi porque estos aspectos presentan rasgos comunes: motivación a partir del entorno cotidiano y valor de la experiencia. Esta se entiende como manipulación, exploraciones diversas y otras pequeñas investigaciones de carácter no manipulativo. Las experiencias son actividades de importancia vital para el alumno, dada su edad, y pueden describirse como: activas, concretas y creativas (8).

Ahora bien, no todas las actividades llegan a ser experiencias de aprendizaje. Tan sólo aquellas que ayuden a desarrollar el pensamiento, adquirir conocimientos, avanzar en las actitudes sociales y suscitar un verdadero interés en el alumno (9).

Pero, para que la experiencia sea más completa, debe ir acompañada de observación directa e indirecta y expresión de lo observado. Cuando el niño expresa sus vivencias del "medio" es un sujeto que reconoce lo observado, lo analiza y lo relaciona: hasta ese momento no ha empezado a conquistar el medio. Los diferentes lenguajes: verbal, gráfico, plástico, matemático, son entre sí complementarios y las vivencias directas tendrán que llegar a ser transferibles de unos lenguajes a otros.

(8) LLOPIS, C.; y SERRANO, M. T.: El área de Experiencias en preescolar y Ciclo Inicial. Madrid, Narcea, 1981 , pág. 39.

(9) TYLER: Principios básicos para el curriculum. Buenos Aires, Troquel, 1975. 


\section{DIFICULTADES PARA REALIZAR EL ESTUDIO DEL MEDIO}

Las dificultades que podemos encontrar a la hora de abordar el estudio del "medio" son las siguientes:

1) Materiales. Debido a la falta de equipamiento de algunos centros.

2) Administrativas. En los colegios falta un verdadero equipo pedagógico que programe en base a una visión interdisciplinar de la actividad escolar. Falta de sincronización entre los distintos profesores.

3) Extraescolares. Oposición por parte de algún organismo en cuanto a proporcionar datos o dejar consultar los archivos.

Salvando estas posibles dificultades, de nada servirá el haber enunciado la conveniencia del estudio del medio en la E. G. B., si el propio maestro no se implica en esta dinámica del "medio" y continúa, en algunos casos, encadenado al libro de texto.

\section{BIBLIOGRAFIA}

BARR, A. S.: Observa e investiga en la ciudad. Kapelusz, Buenos Aires, 1971.

CLARION: La localidad y su entorno: programación para su estudio en la escuela. ICE. Cudad Universitaria. Zaragoza.

DEBESSE-AR VISSET, M.: El entorno en la escuela: una revolución pedagogica. Fontanella, Barcelona, 1974.

FRABBONI, F. y otros: El primer abecedario: el ambiente. Fontanella, Barcelona, 1980.

GEORGE, P.: El medio ambiente. Oikós-Tau, 1972.

HANNOU, H.: El niño conquista el media. Kapelusz, Buenos Aires, 1977.

ICE Universidad de Zaragoza: Programas y experiencias del estudio del entorno. 1978.

OLIVER, J.: Los programas escolares y la investigación del entorno. Escuela Española, Madrid, 1981.

TERRADAS: Ecologia y educación ambiental. Omega, Barcelona, 1978. 